\title{
Effect of Manganese Doping Percentage on Band Gap Energy of Cadmium Sulphide (CdS) Nanofilms Prepared by Electrodeposition Method
}

\author{
Okafor Patricia C. ${ }^{1}$, Ekpunobi A. J. ${ }^{2}$ \\ ${ }^{1}$ Department of Physics, College of Education Nsugbe, Anambra State-Nigeria \\ ${ }^{2}$ Nnamdi Azikiwe University Awka, Anambra state-Nigeria
}

\begin{abstract}
Cadmium sulphide (CdS) nanofilms with different Mn percentage doping were prepared by electrodeposition method at room temperature using aqueous solution of cadmium chloride, manganese chloride, sodium thiosulphate andtriethanolamine as the complexing agent,. The XRD studies showed that the Mn doped CdSnanofilms have cubic structure with crystallite sizes of range 0.288 to $2.739 \mathrm{~nm}$.The thickness of the films determined by optical method were ofrange $2.04 \mathrm{~nm}$ to $20.82 \mathrm{~nm}$. The band gap energy of CdSnanofilms increased with the increasing of Mn percentage doping and their values of range $2.02 \mathrm{eV}$ to 2.35 eV were slightly lower than $2.42 \mathrm{eV}$, the literature value for bulk CdS. The observed decrease in band gap energy values of CdSfilms with different Mn percentage doping may be due to sp-d exchange interaction between the band electrons and localized d-electrons of Mn ions substituting $\mathrm{Cd}^{+2}$ ions. Such Mn doped CdS films could be suitable for applications in thin films solar cells fabrications, photo-thermal and optoelectronic devices.
\end{abstract}

Keywords: Effect of Manganese percentage doping, bandgap energy, Cadmium sulphidenanofilms, Electrodeposition

\section{Introduction}

Recently, there has been an increase in research and development of nanostructured II-VI semiconductor materials owing to their importance in basic scientific researches and potential technological applications [1]. Such nanostructured materials exhibit unusual physical and chemical properties in comparison with their bulk materials, such as size dependent variation of band gap energy and have many potential applications in photochemistry, catalysis and electronic/optical materials [2,3].

Cadmium sulphide (CdS) as an important II-VI semiconductor with direct band gap of $2.42 \mathrm{eV}$ at room temperature is a promising candidate for solar cells, green lasers, photoconductors, light emitting diode and thin film transistors, photochemical catalysis, gas sensors, detectors for laser and infrared, display screen,nonlinear optical materials, various luminescence devices, optoelectronic devicesand so on $[1,2,4,5,6,7,8,9,11,12,13,14]$.Optical constant as an input data in design process of the thin film devices gives the designer an additional tool for optimization of the product design, thus an accurate knowledge of optical constant over wide range of wavelength is essentially important [7].

Transition metal doped semiconductors known as dilute magnetic semiconductors, have attracted wide spread scientific attention due to their prospective applications. The doping of transition metals (such as $\mathrm{Mn}, \mathrm{Fe}, \mathrm{Co}, \mathrm{Ni}$ ) into II VI semiconductors has led to unique optical, electrical, chemical andmechanical properties which cannot be found in undoped materials (15). Dilute magnetic semiconductors (DMSs) offer great opportunity to integrate electrical, optical and magnetic properties into a single material which makes them ideal candidate materials for nonvolatile memory, magneto-optical, futurespintronic devices [1]. Group II - VI semiconducting chalcogenides, such as Cadmium sulphide, owing to its wide band gap energy, is found suitable for use as host material for variety of transition metal dopants [1]..

\section{Literature Review}

The optoelectronic properties, particle sizes and morphologies of nanomaterials have close relation to preparation conditions [11]. Cadmium sulphide can exist in form of stable hexagonal phase or cubic phase or a mixed phase [5]. Cadmium sulphide with cubic structure had been reported by many authors $[6,10,16]$.The transmission of light through dopedCdS films decreases with increasing film thickness and dopant concentration [17, 18]. A shift for absorption edge towards the shorter wavelength with increase in doping concentration has been reported $[17,18,19,20]$. Decrease in band gap can be attributed to the influence of various factors such as grain size, structural parameters, carrier concentration, presence of impurities, deviation from stoichiometry of the film and decrease in the lattice strain [17].

Doping semiconductors with transition metal ions opens up possibilities of forming a new class of materials and new properties of the materials are expected.Transition metals are most interesting impurities as they introduce deep levels in the gap region, which can influence not only optical characteristics but also electrical and magnetic properties thereby influencing their practical applications, [20]. Dilute magnetic semiconductors provide the possibility of tuning parameters such as band gap and lattice constants by varying the composition of the material [19].The variation in band gap can be due to the influence of the various factors such as grain size, structural parameters, carrier concentration, presence of impurities, deviation from stoichiometry of the film and decrease in the lattice strain [17].The decrease in 


\section{International Journal of Science and Research (IJSR) \\ ISSN (Online): 2319-7064 \\ Index Copernicus Value (2013): 6.14 | Impact Factor (2014): 5.611}

the band gap energy reported for transition metaldoped CdS material can be ascribed to $s p-d$ exchange interaction between the band electrons and localized d- electrons of dopant ions substituting $\mathrm{Cd}^{+2}$ ions [16].Controlling the size and dimensionality of DMS structures is an additional powerful way to tune their properties via quantum confinement effects [21].

Different deposition methods had been reported for cadmium sulphide $(\mathrm{CdS})$ thin films, but solution growth techniques are probably the most explored approach.. In this work,electrodeposition method was adopted for the preparation of manganese doped cadmium sulphide (CdS:Mn) nanofilms.Electrodeposition method does not require high temperature and pressure selectivity [5]. Furthermore, this method is scalable with high degree of controllability and reproducibility, hence it is widely applied commercially[ 22]. The electrodeposition process involves multiple reactions which include reduction, formation and crystallization, (Sharma et al., 2004).

The main purpose of this study is to investigate the effect of manganese percentage doping on the band gap energies of CdSnanofilms prepared byelectrodeposition method and to proffer the possible applications of such DMS nanofilms.

\section{Materials and Method}

All the chemical used for the cathodicelectrodeposition of manganese doped cadmium sulphide (CdS:Mn) nanofilms were of analytical grade and all solutions prepared in deionized water (Alpha-Q-millipore). The CdS:Mnnanofilms were prepared from acidic bath containing aqueous solutions of $10 \mathrm{ml}$ of $0.05 \mathrm{M}$ cadmium chloride $\left(\mathrm{CdCl}_{2} \cdot 2 \frac{1}{2} \mathrm{H}_{2} \mathrm{O}\right)$ as $\mathrm{Cd}^{+2}$ ions precursor, $10 \mathrm{ml}$ of $0.05 \mathrm{M}$ manganese chloride $\left(\mathrm{MnCl}_{2} 4 \mathrm{H}_{2} \mathrm{O}\right)$ as $\mathrm{Mn}^{+2}$ ions precursor, $10 \mathrm{ml}$ of $0.05 \mathrm{M}$ sodium thiosulphate $\left(\mathrm{NaS}_{2} \mathrm{O}_{3} .5 \mathrm{H}_{2} \mathrm{O}\right)$ as $\mathrm{S}^{2-}$ ions precursor, $10 \mathrm{ml}$ of $0.05 \mathrm{M}$ tri-ethanolamine (TEA) as a complexing agent. Few drops of $1.0 \mathrm{M}$ hydrochloric acid $(\mathrm{HCl})$ were used to control the $\mathrm{PH}$ of the electrolyte in the reaction bath. Prior to deposition, the ITO glass substrates were degreased with ethanol for 10 minutes; then ultrasonically cleaned with de-ionized water for another 10 minutes and finally dried in a desicator. Thesurface of the platinum plate was thoroughly polished andall glass beakers / measuring cylindersthoroughly washed with de-ionized water.
The experiment was carried out using acidic bath of PH 3, at room temperature, optimum deposition time of 240 seconds and optimum deposition voltage of 4.0 Volts while manganese doping percentage in the reaction bath was varied from $3 \%$ to $23 \%$. The reactions involve chelating of $\mathrm{Cd}^{2+}$ and $\mathrm{Mn}^{2+}$ ions with complexing agent, tri-ethanolamine to form a complex ions, CdMnTEA ${ }^{2+}$ which then react with the $\mathrm{S}^{2-}$ ions produced from sodium thiosulphate solution to form CdMnS compound at the cathode (ITO glass substrate). The deposited CdS: Mn films were rinsed with de-ionized water, dried, annealed at the temperature $250^{\circ}$.C and kept for analysis.

The structural analysis of Mn doped CdSnanofilms was studied by X-ray Mini Diffractometer, model MD 10.The optical studies of manganese doped cadmium sulphidenanofilms were carried out by JENWAY 6405 UVVis Spectrophotometer within the wavelength range of $280 \mathrm{~nm}$ to $1100 \mathrm{~nm}$. The absorption coefficient $\alpha$ of the film samples is determined by the equation;

$$
\alpha=\mathrm{A} / \lambda
$$

where $\mathrm{A}$ is the absorbance of the film and $\lambda$ is wavelength of incident radiation.

Near the absorption edge the absorption coefficient is related to the band gap, Eg by the equation;

$$
\alpha=(\mathrm{hu}-\mathrm{Eg})^{\mathrm{b}} \text {...... }
$$

where $\mathrm{h}$ is the Planck's constant, $\mathrm{U}$ is the frequency of incident radiation, $\mathrm{hU}$ is the photon energy and $\mathrm{b}$ is $\mathrm{a}$ constant for a given transition.

The band gap energy (Eg) of the films are respectively obtained from allowed transition by extrapolating the graph of $\alpha^{2}$ versus (hu) to the point where $\alpha^{2}$ is zero.

\section{Results and Discussion}

The XRD pattern of the CdS:Mn film (with $8 \% \mathrm{Mn}$ ) deposited on ITO glass substrate is shown in Fig. 1. The crystals of CdS:Mn film were of cubic structure with preferential growth along (400) direction and lattice constant of $\mathrm{a}=\mathrm{b}=\mathrm{c}=10.176 \AA$. The crystallite size of the film sample calculated using Debye-Scherrer's formula ranged from $0.2878 \mathrm{~nm}$ to $2.7386 \mathrm{~nm}$ with mean crystallite size of $1.1394 \mathrm{~nm}$.

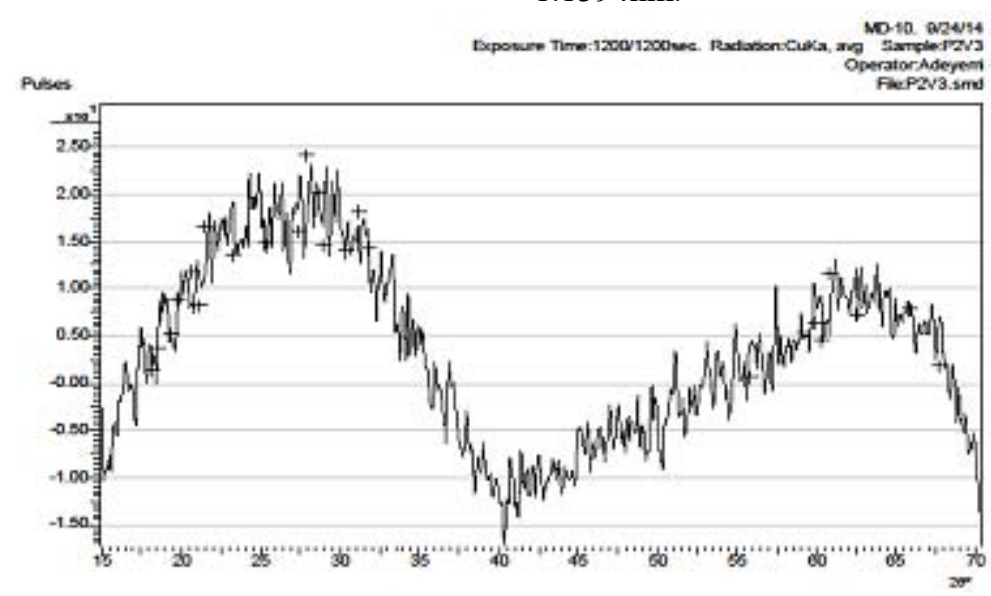

Figure 1: XRD pattern CdS:Mnn with $8 \%$ MnMn doping 


\section{International Journal of Science and Research (IJSR) \\ ISSN (Online): 2319-7064 \\ Index Copernicus Value (2013): 6.14 | Impact Factor (2014): 5.611}

The mean dislocation density value 6.2403 and microstrain of 0.739 may be attributed to interstitially substituted $\mathrm{Mn}$ .impurity atoms or due to adsorbed colloidal $\mathrm{Cd}$ in the film samples. Similar CdS cubic structure had been reported for $\mathrm{CdS}$ prepared using cadmium complex compounds and thioacetamide[10],CBD method at a temperature of $80^{\circ} \mathrm{C}$ [6].and co-precipitation method [16]
The thickness of theMn doped CdS films determined using optical method ranged from $2.04 \mathrm{~nm} 20.82 \mathrm{~nm}$ confirming the nanometer size of the film samples. The transmission spectra of $\mathrm{Mn}$ doped CdS:Mnnanofilms (with different $\mathrm{Mn}$ percentage doping) are shown in Fig.2

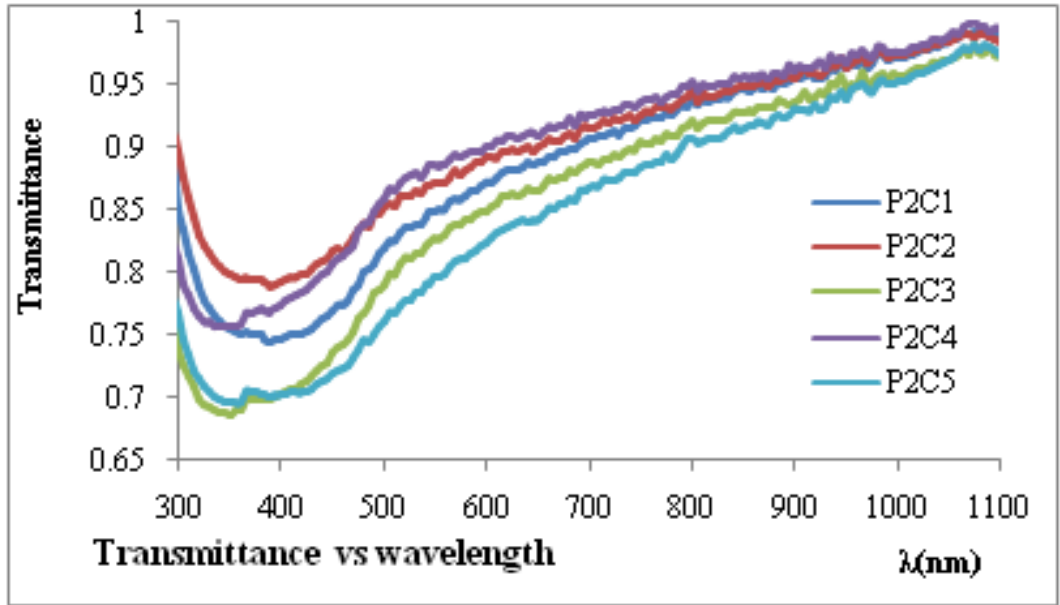

Figure 2: Transmittance spectra of $\mathrm{ZnS}: \mathrm{Mn}$ films with different Mn doping\%

All the films have high transmittance $(>70 \%)$ beyond the absorption edge.At wavelength of $550 \mathrm{~nm}$ in the visible region, the average transmittance of the CdS:Mn film samples increased from 0.87 to 0.88 as Mn doping \% increased from $3 \%$ to $18 \%$ and then decreased to $0.80 \%$ as
Mn doping \% increased to $23 \%$. The high transmittance of the film samples may be ascribed to the thinness of the films. The optical absorption spectra of CdS:Mnfilms with different Mn percentage doping are shown in Fig. 3.

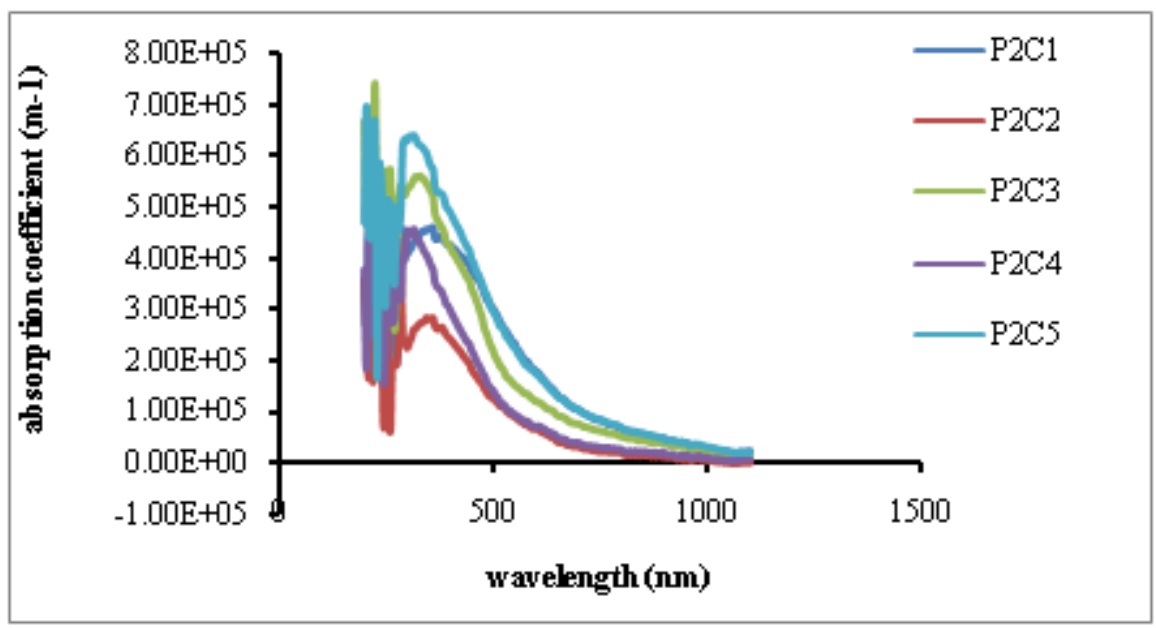

Figure 3: Absorption spectra of $\mathrm{ZnS}: \mathrm{Mn}$ films with different Mn doping\%

The absorption coefficient $(\alpha)$ of all the CdS:Mn films were relatively high in the wavelength range of $300-350 \mathrm{~nm}$ and zeroed from the wavelength of $700 \mathrm{~nm}$.At wavelength of $550 \mathrm{~nm}$ in the visible region, the average absorption coefficient of Mn dopedCdS films decreased from $0.25 \times 10^{6}$ to $0.10 \times 10^{6}$ as Mn doping \% increased from $3 \%$ to $8 \%$ and then increased to $0.25 \times 10^{6}$ as $\mathrm{Mn}$ doping \% increased to $23 \%$. However, the film sample doped with $18 \% \mathrm{Mn}\left(\mathrm{P}_{2} \mathrm{C}_{4}\right)$ exhibited low absorption coefficient of $0.10 \times 10^{6}$. The obtained magnitude of absorption coefficient $10^{6}$ is within the range of $10^{6}$ to $10^{-7}$ required for the fabrication of semiconductor thin film solar cells [24]. The absorption edge of all theCdS:Mn films fall within the shorter wavelength range $300 \mathrm{~nm}-320 \mathrm{~nm}$ compared to $515 \mathrm{~nm}$ reported for bulk cubic $\mathrm{CdS}$, thus suggesting that they are blue shifted.[10]. The blue shift in absorption edge may be attributed to quantum confinement of the excitons present in the film samples, resulting in a more discrete energy spectrum of the individual particles [2]. Similar results had been reported for $\mathrm{Cu}, \mathrm{Fe}$ co-doped $\mathrm{CdS}$ [1], Mn,Ce co-doped $\mathrm{CdS},[11], \mathrm{Mn}$ - doped CdS [4]andCl - doped CdS films.[17]Such films with high absorption coefficient in the visible region could be employed as widow materials in variousphoto-thermal and optoelectronic devices $[1,25]$.

The optical band gap values of CdS:Mnnanofilms were obtained by extrapolating the linear part of the curves of $\alpha^{2}$ versus hu to huaxis where $\alpha=0$ as shown in Fig. 4 .

\section{Volume 4 Issue 12, December 2015}




\section{International Journal of Science and Research (IJSR)

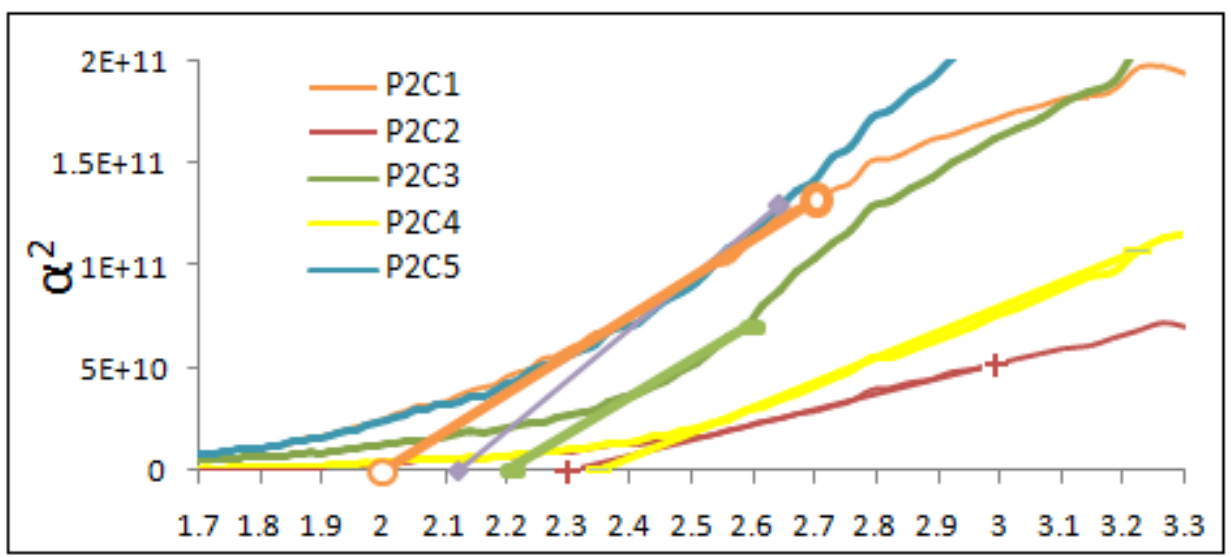

Figure 4: Plot of $\alpha^{2}$ versus hu for $\mathrm{ZnS}: \mathrm{Mn}$ films with different $\mathrm{Mn}$ doping\%

The band gap energy of CdSnanofilms increased from $2.02 \mathrm{eV}$ to $2.35 \mathrm{eV}$ as $\mathrm{Mn}$ doping $\%$ increased from $3 \%$ to $18 \%$ and then decreased to $2.12 \mathrm{eV}$ as $\mathrm{Mn}$ doping \% increased to $23 \%$. The highest optical band gap value $(2.35 \mathrm{eV})$ was obtained from the film sample $\left(\mathrm{P}_{2} \mathrm{C}_{4}\right)$ doped with $18 \% \mathrm{Mn}$. The results revealed that the band gap energy values oftheCdS:Mnnanofilms ofrange $2.02 \mathrm{eV}$ to 2.35 eVwerelower than $2.42 \mathrm{eV}$ reported for forundopedCdS[5] but compare favorably with the band gap energy range $2.30 \mathrm{eV}$ to $2.38 \mathrm{eV}$ reported for Mn doped CdS films prepared by chemical bath deposition method [4],2.36eV for mercury doped $\mathrm{CdS}$ films[25],2-35eV for $\mathrm{Cu}$ doped $\mathrm{CdS}$ [16], $2.20 \mathrm{eV}$ for $\mathrm{Cu}, \mathrm{Fe}$ co-doped $\mathrm{CdS}$ [1] and $2-35 \mathrm{eV}$ for undoped,CdS [7]. Although the obtained band gap values are lower than the CdS, bulk value, their value increase with the increasing of percentage doping, The decrease in the band gap energy observed in the doped CdSnanofilms may be due to $\mathrm{sp}-\mathrm{d}$ exchange interaction between the band electrons and localized d- electrons of $\mathrm{Mn}$ ions substituting $\mathrm{Cd}^{+2}$ ions [16]. The difference in the band gap energy values of CdS with different Mn content confirmed that Mn doping \% strongly influenced the band gap energy of the film samples Such directband gap Mn doped CdSnanofilms with a wide range of band gap energy values could be employed for the thin films solar cells fabrications and various optoelectronic devices applications $[1,2,4,5,7]$.

\section{Conclusion}

Manganese doped cadmium sulphide (CdS:Mn) nanofilms were successfully prepared by electrodeposition method using acidic bath containing aqueous solution of cadmium chloride, manganese chloride, sodium thiosulphate and a complexing agent, triethanolamine. The XRD pattern of CdS:Mnnanofilms revealed that the crystals of the film have cubic structure. The thickness of the films were found to be in nanometer sized range. We investigated the effect of manganese percentage doping on band gap energy of CdSnanofilms. The results showed that the obtained band gap energy values were lower than $2.42 \mathrm{eV}$ reported for the undoped bulkCdS but increase with the increasing ofMn percentage doping. Such CdS:Mnnanofilms with wide range of direct band gap energy values could be employed for thin films solar cells fabrications and various optoelectronic devices applications.
We recommend that more research work be carried out on Mn doped CdSnanofilms using other methods of deposition.

\section{Acknowledgement}

The authors are thankful to Crystal Growth \& Characterization Laboratory, Solid State \& Materials Science Division, University of Nigeria, Nsukka for providing laboratory facilities for the growth of the film samples and Engineering Materials Development Institute, Akure-Nigeria for extending X-ray diffraction and UV-Vis Spectophotometer facilities for the present work.

\section{References}

[1] Hasanzadeh J.;Shayesteh F.S; and Ziabari A.A. (2014). "Effect of $\mathrm{PH}$ on the Optical properties of doped $\mathrm{CdS}(\mathrm{Cu}, \mathrm{Fe})$ nanoparticles incorporated in $\mathrm{TG}$ as a capping agent", ACTA PhysicaPolonica A, 120, 713716

[2] Khalid T. A-R; Nada K.A; Zainb J.S. (2013); "Structural and Optical Characterization of $\mathrm{Cu}$ and Nidoped CdS nanoparticles", Int. J. Electrochem. Sci. 8(2013), 5594-5604

[3] Dang Q; Genwang.W; Christophers M.S and Kenneth J.K; (2009); "Cadmium (Zinc) manganese sulphidenanocrystalline $\left(\mathrm{Cd}_{1-\mathrm{x}} \mathrm{Mn}_{\mathrm{x}} \mathrm{S}\right.$ and $\left.\mathrm{Zn}_{1-\mathrm{x}} \mathrm{Mn}_{\mathrm{x}} \mathrm{S}\right)$ dilute magnetic semiconductors: synthesis, annealing and effects of surface oxidation on magnetic properties", Arabian Journal of Chemistry, 41, 63-68.

[4] Alvan, S.H; Abdulhadi K.T; Attalia B.H; (2010); "Optical, electrical and structural properties of $\mathrm{Mn}$ doped CdS prepared by CBD"; Journal of College of Education, 1(1), 76-90

[5] Anuar K.I; Zainal Z.I; Nagalmgam S; Muhammed N, Razak S. (2005); "Effects of deposition periods and solution temperatures towards the properties of $\mathrm{CdS}$ thin films prepared in the presence of sodium tartrate"; Materials Science, 11 (2), 10-15.

[6] Choi J.Y; Kim K.Y, Yoo J.B. and Kim D. (1998); "Properties of $\mathrm{CdS}$ thin films deposited by ultrasonication"; Sol. Energy 64(1-3), 41 -47

[7] Ziaul, R.K; Zulfequar, M; Shahid K.M; (2010); "Effect of thickness on structural and optical properties of thermally evaporated cadmium sulphide polycrystalline thin films"; Chalcogenide Letters 7(6), 431-438

\section{Volume 4 Issue 12, December 2015}




\section{International Journal of Science and Research (IJSR) \\ ISSN (Online): 2319-7064}

Index Copernicus Value (2013): 6.14 | Impact Factor (2014): 5.611

[8] Murugadoss C. (2012); “ Synthesis of high quality and monodisperse CdS: $\mathrm{Mn}^{2+} / \mathrm{ZnS}$ and CdS: $\mathrm{Mn}^{2+} / \mathrm{CdS}$ core shell nanoparticles superlattices and microstructures"; 52 (2012), 1026-1042

[9] Srinivasa, R; Bajesh Kumar B; Venkata C.G; Rajagopel R.V; Subba R.T; (2011); “ Structural properties of Ni doped CdS". J. Nano. Electron. Phys. 3(1), 620-625.

[10] Dumbrava A; Badea C; Prodan G. Ciupina V; (2010); "Synthesis and Characterization of Cadmium sulphide obtained at room temperature; Chalcogenide Letters, 7(2), 111-118

[11] Sreenivas, M; Harish G.S and Reddy P.S. (2014), "Synthesis and Characterization of $\mathrm{Mn}, \mathrm{Ce}$ co-doped CdS nanoparticles synthesized via co-precipitation method"; International Journal of Modern Engineering Research. (IJMER),4(9), 10-16

[12] Verma, P; Manoj, G.S; Pande, A.C. (2010); "Organic capping effect and mechanism in Mn-doped CdSnano composites"; Physics B: Condensed Matters, 405 (5), 1253-1257.

[13] Liu, S; Liu, F; Guo, H; Zhang, Z; Wang, Z; (2000); "Surface states induced photoluminescence from $\mathrm{Mn}^{2+}$ doped CdS nanoparticles"; Solid State Communications 115 (2000), 615-618

[14] Cui, H.N; Teixero, V; Meng L.J; Zhang H.J. (2004); "Studies on microstructure bi-layer film of ultrasonic dipped CdS and DC sputtered indium tin oxide (ITO)!; Thin solid films, 444-448, 663-668

[15] Thi, T.M; Tinah I.V; Van, B.H; Ben P.V. and Trung V.Q; (2012); "The effect of polyvinylpymolidone on the optical properties of the Ni-doped ZnSnanocrystalline thin films synthesized by chemical method"; Journal of Nanomaterials, 2012, Article ID 528047

[16] Sreelekha, N; Subramaniam, K; Murali G; Giribabu, G; Vijayalakhimi, R.P. Madhusudhana R. (2014); "Effect of $\mathrm{Cu}$ doping on structural and optical properties of CdS nanoparticles"; International Journal of Chem. Tech Research, CODEN USA, 6(3), 21132116

[17] Al-Shammari, A.;,Mulla A.F and Al-Dhafiri, A.M; (2005); "Preparation and characterization of chlorine doped Cadmium sulphide $(\mathrm{CdS}: \mathrm{Cl})$ thin films and their applications."; M.Sc Thesis, King Saud University, College of Science, Department of Physics, Riyadh. Saudi Arabia.

[18] GodeF.andGumus, C; (2009); "Influences of copper and manganese concentrations on the properties of polycrystalline $\mathrm{ZnS}: \mathrm{Cu}$ and $\mathrm{ZnS}: \mathrm{Mn}$ thin films", Journal of Optoelectronics and Advanced materials, 11(4), 429-436

[19] Rojas-Hernadez, A.G; Mendivil-Reynoso, T; AcostaEnriquez, M.C; (2012); “Comparison of properties of cadmium, copper and lead sulphides thin films grown by CBD"; Chalcogenide Letters, 9 (3), 121-126.

[20] Pathak, C.S; Pathak, P.K; Kumar, P; Mandal, M.K; (2012); "Characterization and Optical properties of $\mathrm{Ni}^{2+}$ doped $\mathrm{ZnS}$ nanoparticles"; Journal of Ovonic Research 8(1), 15-20

[21] Kadiran, F; Mao D, Song Wal;Ohno, T; McCandless B; (2000); "Properties of electrodeposited CdS for photovoltaic device with comparison to $\mathrm{CdS}$ prepared by other methods"; Turk. J. Chem. 24, 21-33

[22] Sharma, R.K, Rostigi, A.C; Singh, G; (2004); "Electrochemical growth and characterization of manganese telluride thin films" Materials Chemistry and Physics, 84 (2004), 46-51

[23] Ilenikhena, P.A. (2008); "Comparative studies of improved copper sulphide $(\mathrm{CuS})$ and Zinc sulphide (ZnS) thin films at $320 \mathrm{~K}$ and possible applications"; African Physical Review, 2(7), 59-67

[24] Eleruja, M.A; Adedeji, A.V; Olofinjana, B; Akinwunmi, O.O; Ojo, I.A; Egharaba, G.O; Osasona O. and Ajayi, E.O.B; (2010); "Preparation and characterization of mercury cadmium sulphide thin films"; Journal of Non-Oxide Glasses, 2(4), 175-185. 